\title{
HUBUNGAN INFORMASI TENTANG ALAT KONTRASEPSI DENGAN MOTIVASI PEMILIHAN ALAT KONTRASEPSI IMPLANT DI DESA POREH WILAYAH KERJA UPT. PUSKESMAS LENTENG KEC. LENTENG KAB. SUMENEP
}

\author{
Eva Nurhidayati, Program Studi Kebidanan Universitas Wiraraja \\ e-mail : evanurhidayati06@gmail.com \\ Dian Permatasari, Program Studi Kebidanan Universitas Wiraraja \\ e-mail: dian_ashadi@yahoo.com
}

\begin{abstract}
The family planning program $(K B)$, which has been running for 40 years, is able to prevent a population increase of about 100 million people. BKKBN expects this year to increase the knowledge and skills of acceptor families. Namely about parenting and child development and development. In addition, improving the quality of elderly families, as well as the family's economic income through the group of productive economic business activities. To know Information About Relationship With Contraceptive Implant Contraceptive Selection Motivation.

The study design used is an analytical method with cross sectional design.The population in this study as many as 633 large maternal EFA and EFA sample40 mothers. Engineering samples are used random sampling. The data got fromthe village of the District Poreh Lanteng and questionnaire data analysis while using the Spearman rank correlation test.

The results showed the majority (62.5\%) mothers receive less information, the majority (70.0\%) mothers had a negative motivation in Contraceptive Implant Selection. Statistical research results obtained using the Spearman rank correlation test Relationship With Information About Contraception Contraceptive Implant Selection Motivation in can sig $\rho=0.000$ $<\alpha=0.05)$ so that $H_{0}$ is rejected, which means there is the Relationship Between Information About Motivation Election With Contraceptives Contraception.

The conclusion of this study is the lack of information that pussy mother and motivation that can negatively affect the Selection Tool contraceptives.
\end{abstract}

Keywords : Information, Motivation, Ctraceptive Implant

\section{PENDAHULUAN}

Program keluarga berencana $(\mathrm{KB})$ yang telah berjalan selama 40 tahun mampu mencegah terjadinya pertambahan penduduk sekitar 100 juta jiwa. BKKBN mengharapkan tahun ini terjadi peningkatan pengetahuan dan keterampilan keluarga akseptor. Yakni mengenai pengasuhan dan pembinaan tumbuh kembang anak. Selain itu peningkatan kualitas keluarga lansia, serta pendapatan ekonomi keluarga melalui kelompok kegiatan usaha ekonomi produktif.

Hasil SDKI 2016 mencatat tingkat prevalensi pemakaian $\mathrm{KB}$, yang menunjukkan peserta KB di antara PUS mencapai 61,9\% (suatu cara). Sebanyak 57,9\% memakai KB modern, meningkat sebesar $0,5 \%$ dari $57,4 \%$ dalam 5 tahun terakhir. Penggunaan KB didominasi oleh alat kontrasepsi jangka pendek, mencapai $31,9 \%$. Tingkat pemakaian metode $\mathrm{KB}$ jangka panjang (MKJP), sebesar $10,6 \%$.

Berdasarkan data dari Dinas Kesehatan Kabupaten Sumenep menunjukkan bahwa pada tahun 2016 di daerah Kecamatan Lenteng terdapat 216 akseptor KB baru yang memakai alat kontrasepsi implan (Dinkes Kab. Sumenep, 2017). Berdasarkan data Kecamatan Lenteng Kabupaten Sumenep pada tahun 2017 diperoleh data sebagai berikut :

\begin{tabular}{ccccc}
\hline N & Nama desa & Sasaran & Capaian & $\%$ \\
\hline 1 & Lenteng Timur & 15 & 9 & 60 \\
2 & Lenteng Barat & 20 & 13 & 65 \\
3 & Poreh & 17 & 4 & 23,52 \\
4 & Ellak Laok & 19 & 10 & 52,63 \\
5 & Ellak Daya & 17 & 13 & 76,47 \\
6 & Daramista & 12 & 8 & 66,67 \\
7 & Jambu & 12 & 6 & 50 \\
8 & Cangkreng & 16 & 7 & 43,75 \\
9 & Meddelan & 25 & 31 & 124 \\
10 & Sendir & 12 & 8 & 8 \\
\hline
\end{tabular}


Berdasarkan tabel 1.1 diatas, menunjukkan bahwa di Desa Poreh cakupan implant masih di bawah target dan terendah, seharusnya yang harus di capai sampai bulan Desember tahun 2017 adalah sebesar 70\% sedangkan di Desa Poreh mencapai 23,52\%. Sehingga terdapat kesenjangan $23,52 \%$ dari target $70 \%$ tahun 2017. Di lihat dari fakta tersebut, maka yang menjadi fokus dalam permasalahan penelitian ini adalah rendahnya cakupan metode kontrasepsi Implant di Desa Poreh wilayah kerja UPT Puskesmas Lenteng tahun 2017 yang mencapai $23,52 \%$ dari target $70 \%$ dibandingkan dengan kontrasepsi hormonal yang lain Implant mempunyai efek samping perubahan berat badan yang lebih banyak terjadi pada penggunanya.

Pemakaian kontrasepsi hormonal dapat meningkatkan proses pembentukan kolesterol dan lemak sehingga menyebabkan peningkatan berat badan pada pengguna implan (Nining, 2014). Kenaikan BB rata-rata untuk setiap tahun berbeda antara 2,3-2,9 kg. sedangkan penurunan $\mathrm{BB}$ rata rata untuk setiap tahun antara 1,6-1,9.

\section{METODE PENELTIAN}

Dalam penelitian ini penulis menggunakan metode penelitian analitic correlational. Pendekatan yang digunakan adalah dengan studi cross sectional.

Populasi dalam penelitian ini yaitu seluruh PUS yang mangikuti KB di Desa Poreh Kecamatan Lenteng Kabupaten Sumenep Januari- April Tahun 2018 dengan jumlah 633 orang.

Teknik sampling menggunakan probability sampling dengan jenis simple random sampling. Sampel penelitian ini sebagian PUS yang mengikuti KB Di Desa Poreh Kecamatan Lenteng dari bulan JanuariApril Tahun 2018 sebanyak 40 orang.

Variabel independen dalam penelitian ini yaitu informasi alat kontrasepsi. Variabel dependen pada peneletian ini motivasi pemilihan alat kontrasepsi Implant.

Instrumen yang akan digunakan peneliti untuk mengetahui apakah ada korelasi tentang informasi dengan motivasi dalam pemilihan $\mathrm{KB}$ menggunakan lembar kuesioner.
Dalam analisis data menggunakan uji korelasi Rank Spearman dengan menggunakan program SPSS 20 for windows dengan tingkat kemaknaan $\mathrm{P}=0,05$ artinya bila nilai $\mathrm{P} \leq 0.05$ maka $\mathrm{H}_{0}$ ditolak.

\section{HASIL PENELITIAN}

1. Umur

\begin{tabular}{cccc}
\hline No. & Umur & F & $\%$ \\
\hline 1. & $<20$ tahun & 2 & 5 \\
2. & 20-30 tahun & 24 & 60 \\
3. & $>30$ tahun & 14 & 35 \\
\hline & Total & 40 & 100 \\
\hline
\end{tabular}

Sebagian besar responden berumur 20-30 tahun sebanyak 24 orang $(60,0 \%)$.

2. Pendidikan

\begin{tabular}{cccc}
\hline No & Pendidikan & F & $\%$ \\
\hline 1. & SD & 25 & 62,5 \\
2. & SMP & 10 & 25 \\
3. & SMA & 3 & 7,5 \\
4. & PT & 2 & 5 \\
\hline & Total & 40 & 100 \\
\hline
\end{tabular}

Sebagian besar responden berpendidikan Sekolah Dasar sebanyak 25 orang $(62,5 \%)$.

3. Pekerjaan Ibu

\begin{tabular}{clcc}
\hline No & Pekerjaan Ibu & F & $\%$ \\
\hline 1. & IRT & 16 & 40 \\
2. & Petani & 22 & 55 \\
3. & Pegawai & 2 & 5 \\
\hline & Total & 40 & 100
\end{tabular}

Sebagian besar responden bekerja ibu sebagai petani yaitu sebanyak 22 orang $(55,0$ $\%)$.

4. Pekerjaan Suami

\begin{tabular}{cccc}
\hline No & Pekerjaan suami & F & $\%$ \\
\hline 1. & Pegawai & 2 & 5 \\
2. & Petani & 27 & 67,5 \\
3. & Swasta & 11 & 27,5 \\
\hline & Total & 40 & 100
\end{tabular}

Sebagian besar responden bekerja suami sebagai petani yaitu sebanyak 27 orang $(67,5 \%)$.

5. Jumlah Anak

\begin{tabular}{cccc}
\hline No. & Jumlah anak & F & $\%$ \\
\hline 1. & 1 (satu) & 9 & 22,5 \\
\hline 2. & 2 (dua) & 17 & 42,5 \\
\hline 3. & $>3(>$ tiga) & 14 & 35 \\
\hline & Total & 40 & 100 \\
\hline
\end{tabular}


Hampir setengahnya responden yang mempunyai jumlah anak yaitu sebanyak 17 orang $(42,5 \%)$.

6. Informasi Tentang Alat Kontrasepsi Responden

\begin{tabular}{cccc}
\hline No & Informasi & F & $\%$ \\
\hline 1. & Baik & 5 & 12,5 \\
2. & Cukup & 10 & 25 \\
3. & Kurang & 25 & 62,5 \\
\hline & Total & 40 & 100
\end{tabular}

Berdasarkan di atas dapat di ketahui dari 40 responden sebagian besar mempunyai informasi yang kurang sebanyak 25 responden $(62,5 \%)$

7. Motivasi Responden Dalam Pemilihan Alat Kontrasepsi Implant.

\begin{tabular}{cccc}
\hline No & Motivasi & F & $\%$ \\
\hline 1. & Positif & 12 & 30 \\
2. & Negatif & 28 & 70 \\
\hline & Total & 40 & 100 \\
\hline
\end{tabular}

Berdasarkan tabel dapat diinterpretasikan dari 40 responden sebagian besar mempunyai motivasi negatif sebanyak 28responden $(70,0 \%)$.

8. Hubungan Informasi Tentang Alat Kontrasepsi Dengan Motivasi Pemilihan Alat Kontrasepsi Implant

\begin{tabular}{ccccccc}
\hline \multirow{2}{*}{$\begin{array}{c}\text { Informasi } \\
\text { kontrasepsi }\end{array}$} & \multicolumn{4}{c}{ Motivasi } & \multirow{2}{*}{ Jumlah } \\
\cline { 2 - 6 } & $\mathrm{N}$ & $\%$ & $\mathrm{~N}$ & $\%$ & $\mathrm{~N}$ & $\%$ \\
\hline Baik & 2 & 40 & 3 & 60 & 5 & 100 \\
Cukup & 3 & 30 & 7 & 70 & 10 & 100 \\
Kurang & 7 & 28 & 18 & 72 & 25 & 100 \\
\hline Jumlah & 1 & 30 & 28 & 70 & 40 & 100 \\
\hline Pada & \multicolumn{4}{c}{ kelompok } & \multicolumn{3}{c}{ responden } & yang
\end{tabular}
mempunyai informasi tentang alat kontrasepsi yang baik sebagian besar bersikap negatif dalam memakai alat kontrasepsi yaitu sebanyak 3 responden (60\%). pada kelompok responden yangalat kontrasepsi yang mempunyai informasi yang hampir seluruhnya bersikap negatif dalam memakai alat kontrasepsi yaitu sebanyak 7 reponden (28\%). Pada kelompok responden yang mempunyai informasi tentang alat kontrasepsi yang kurang hampir seluruhnya bersikap negatif dalam memakai alat kontrasepsi yaitu sebanyak 18 responden (72\%).

Berdasarkan hasil uji statistik korelasi rank spearman dengan bantuan software
SPSS 20.0 di dapatkan nilai signifikan $\rho=0,000$ sedangkan $\alpha=0,05$ dengan demikian $\rho<\alpha$ yang berarti Ho di tolak yang berarti ada hubungan yang kuat dan arahnya negatif antara informasi tentang alat kontrasepsi dengan motivasi pemilihan alat kontrasepsi implant Di Desa Poreh Kecamatan Lenteng Kabupaten Sumenep Tahun 2018.

\section{PEMBAHASAN}

\section{Informasi Ibu Tentang Alat Kontrasepsi Di Desa Poreh Wilayah Kerja UPT Puskesmas Lenteng Kecamatan Lenteng Kabupaten Sumenep Tahun 2018}

Dari 40 responden PUS Di Desa Poreh Wilayah Kerja UPT Puskesmas Lenteng Kecamatan Lenteng Kabupaten Sumenep, sebagian besar mempunyai informasi yang kurang, yaitu sebanyak 19 responden $(62,5 \%)$.

Informasi adalah data yang telah di klasifikasikan dan diterapkan untuk di gunakan dalam proses pengambilan keputusan . Pemberian informasi ini dilakukan setelah mendengarkan dengan aktif masalah klien dan pertanyaan klien tentang informasi. Pemberian informsi tentang keadaan dan kebutuhan klien dan informasi yang diberikan sesuai kondisi dan kebutuhan klien (Handayani,Sri 2009). Adapun faktor-faktor yang mempengaruhi informasi diantaranya adalah sebagai berikut :

1) Umur

Berdasarkan tabel umur menunjukkan bahwa sebagian besar yaitu $(60,0 \%)$ responden cenderung pada umur 20-30 tahun. Kenyataan ini sangatlah sesuai dengan teori yang ada, yang mana kenyataan dilapangan menunjukkan semakin bertambah dewasa semakin penuh pertimbangan tingkat kematangan dan kekuatan seseorang, akan lebih matang dalam berfikir dan bekerja.

Sedangkan menurut Huclok (1998) semakin cukup umur, tingkat kematamgan dan kekuatanseseorang akan lebih matang dalam berfikir dan bekerja (Wawan dan Dewi, 2010).

\section{2) Pendidikan}

Berdasarkan hasil Tabel pendidikan Bahwa Sebagian besar pendidikan terakhir adalah Sekolah Dasar, yaitu sebanyak 24 responden $(60,0 \%)$. Informasi yang di dapatkan tentang $\mathrm{KB}$ sangat kurang. 
Pendidikan adalah arahan yang diberikan kepada individu dan individu lain terhadap sesuatu hal agar dapat paham. Makin tinggi pendidikan seorang individu semakin mudah pula seorang individu menerima informasi dan akhirnya makin banyak pula pengetahuan yang dimilikinya.

\section{3) Pekerjaan Ibu}

Berdasarkan tabel pekerjaan ibu Sebagian besar responden bekerja ibu sebagai petani, yaitu sebanyak 24 orang $(60,0 \%)$. sehingga peluang untuk menerima informasi tentang alat kontrasepsi entah pada saat posyandu atau dari berbagai pelayanan kesehatan lebih sedikit daripada dengan ibu yang memiliki pekerjaan sebagai IRT biasanya mereka banyak memiliki waktu untuk datang menerima informasi .

Pekerjaan adalah lambang status individu dimasyarakat. Pekerjaan merupakan jalan untuk mendapatkan penghasilan materi.

Dari pernyataan diatas menunjukkan bahwa dari faktor umur, pendidikan, dan pekerjaan ibu mempengaruhi motivasi ibu dalam pemilihan alat kontrasepsi di Desa Poreh Wilayah Kerja UPT. Puskesmas Lenteng Kabupaten Sumenep.

Upaya yang perlu di lakukan adalah untuk meningkatkan motivasi ibu dalam memilih alat kontrasepsi yaitu dapat di lakukan oleh pemerintah bersama Dinas Kesehatan dan para tenaga kesehatan, terutama bidan dengan cara memberikan motivasi, informasi, dan penyuluhan secara tertur seputar tentang pentingnya alat kontrasepsi.

Dari hasil kuesioner untuk mengetahui informasi dan motivasi ibu disini yaitu dengan menanyakan isi materi untuk mengukur informasi dari subjek penelitian atau responden tentang informasidan bagaimana motivasi ibu dalam memilih alat kontrasepsi. Informasi ibu tentang alat kontrasepsi implant yang masih kurang dapat dilihat dari frekuensi kunjungan ke polindes ibu-ibu yang tidak menggunakan alat kontrasepsi implant tersebut.

Dari hasil survey dilapangan banyak ibu tingkat informasinya adalah kurang, dimana pada hasil kuesioner banyak ibu yang memiliki informasi yang kurang tentang alat kontrasepsi implant. Kesenjangan antara teori dan keadaandi lapangan, yang menunjukkan bahwa tingkat informasi sangat berpengaruh bagi seseorang dalam memahami, membuat suatu keputusan, serta mengambil tindakan terhadap suatu hal. Hal tersebut menandakan semakin baik tingkat informasi, maka ibu semakin bersikap baik dalam menggunakan alat kontrasepsi implant. Hasil temuan di lapangan di dapatkan dari ibu yang menjadi responden kemungkinan penyebab rendahnya adalah kurangnya dalam memilih alat kontrasepsi implant.

\section{Motivasi Ibu Terhadap Pemilihan KB Implant Di Desa Poreh Kecamatan Lenteng Kabupaten Sumenep Tahun 2018}

Diketahui bahwa sebagian besar mempunyai informasi yang bersikap negatif dalam pemilihan alat kontrasepsi implant, yaitu sebanyak 31 responden $(77,5 \%)$.

Adapun yang mempengaruhi motivasi pemilihan alat kontrasepsi implant diantaranya adalah sebagai berikut :

1) Pekerjaan Suami

Berdasarkan Tabel pekerjaan suami sebagian besar bekerja suami sebagai petani, yaitu sebanyak 26 responden $(65,0$ $\%)$. Dapat disimpulkan bahwa pekerjaan sebagai petani lebih memotivasikan untuk tidak memakai alat kontrasepsi implant, hal ini bisa terjadi karena salah satunya ialah faktor ekonomi dan ini sangat mempengaruhi.

Dari hasil kuesioner untuk mengetahui informasi dan motivasi ibu disini yaitu dengan menanyakan isi materi untuk mengukur motivasi dari subjek penelitian atau responden tentang isi materi untuk mengukur motivasi dari subjek penelitian atau responden tentang informasi yang di terima bagaimana motivasi dalam memakai alat kontrasepsi implant ini mempunyai persepsi bahwa ia sudah mengalami sehingga tidak butuh nasehat untuk menggunakan $\mathrm{Kb}$ dan akan mempengaruhi pada motivasi ibu dalam pemiliha alat kontrasepsi implant yang masih kurang dapat dilihat dari frekuensi kunjungan pemilihan alat kontrasepsi implant.

Upaya yang perlu di lakukan adalah terutama bidan, dengan cara memberikan motivasi, informasi, dan penyuluhan secara 
teratur dan kontinyu tentang pemilihan alat kontrasepsi agar ibu lebih mengerti atau memahami manfaat tentang alat kontraepsi dan efek sampingnya sesuai yang telah di tetapkan.

\section{2) Jumlah Anak (Paritas)}

Berdasarkan hasil Tabel paritas Hampir setengahnya responden yang mempunyai jumlah anak, yaitu sebanyak 17 orang $(42,5 \%)$. Di sini dapat di simpulkan meskipun jumlah anak hampir setengah tetapi para calon ibu hanya memiliki pendapat yang menurutnya ibu yang memiliki lebih dari satu orang anak yaitu multipara atau grande multipara mempunyai kecendrungan untuk tidak melakukan tindakan yang di harapkan dan bersikap negatif dalam pemilihan alat kontrasepsi implant.

Paritas adalah banyaknya kelahiran hidup yang di punyai oleh seorang wanita (BKKBN, 2006), senada dengan pendapat di atas, Prawirohardjo (2009). Berbeda dengan definisi yang di catat oleh JHPIGO (2008). Ibu yang pertama kali memakai alat kontrasepsi implant merupakan hal yang sangat baru menurutnya, sehingga termotivasi memilih untuk memakai alat kontrasepsi kepada tenaga kesehatan, sebaliknya ibu yang sudah berpengalaman menggunakannya atau yang sudah berkali-kali pakai akan lebih mudah atau merasa senang memilih alat kontrasepsi implant.

Upaya yang perlu dilakukan untuk tingkat paritas ibu yang tinggi yang bersikap negatif yaitu dapat di lakukan oleh pemerintah bersama dinas kesehatan dan para tenaga kesehatan, terutama bidan dengan cara memberikan motivasi, informasi, dan agar ibu lebih mengerti atau memahami macam- macam alat kontrasepsi.

Motivasi adalah dorongan, yang mendorong seseorang untuk mencapai tujuan tertentu yang. (Hamzah, 2007). Menurut Mukiyat, motivasi adalahSetiap perasaan yang sangat mempengaruhi keinginan seseorang sehingga orang itu didorong untuk bertindak, Pengaruh kekuatan yang menimbulkan perilaku, dan Proses dalam diri seseorang yang menentukan gerakan atau tingkah laku(Asnawi, 2007).

\section{Hubungan Informasi Alat Kontrasepsi Dengan Motivasi Pemilihan Alat Kontrasepsi Implant}

Berdasarkan hasil uji statistik korelasi rank spearman yaitu $\mathrm{H}_{\mathrm{O}}$ ditolak, yang artinya ada hubungan yang kuat dan arahnya negatif antara informasi tentang alat kontrasepsi dengan motivasi pemilihan alat kontrasepsi implant di Desa Poreh Kecamatan Lenteng Kabupaten Sumenep tahun 2018.

Dapat di ketahui bahwa informasi tentang alat kontrasepsi yang mempunyai infomasi yang baik sebagian besar bersikap positif dalam memakai alat kontrasepsi yaitu sebanyak 2 responden $(66,7 \%)$,informasi tentang alat kontrasepsi yang mempunyai informasi yang cukup hampir seluruhnya bersikap negatif dalam memakai alat kontrasepsi yaitu sebanyak 15 reponden $(83,3 \%)$, dan informasi tentang alat kontrasepsi yang mempunyai informasi yang kurang hampir seluruhnya bersikap negatif dalam memakai alat kontrasepsi yaitu sebanyak 15 responden $(78,9 \%)$.

Informasi adalah data yang sudah di olah menjadi bentuk yang memiliki arti bagi si penerima dan bermanfaat bagi pengambilan keputusan saat ini atau mendatang. Menurut hasil penelitian Musdalifah1, Mukhsen Sarake 1, Rahma1(2013) hasil analisis bivariat terdapat 5 variabel yang mempunyai hubungan yang signifikan. Hasil analisis menunjukkan bahwa ada hubungan antara pemberian informasi dengan pemilihan alat kontrasepsi.

Usia adalah umur individu yang terhitung mulai saat dilahirkan sampai berulang tahun, (Elisabeth $\mathrm{BH}$ yang dikutip Nursalam (2003)). sehingga dalam memilih alat kontrasepsi, mereka sudah tahu KB mana yang lebih cocok untuk di pakai. Pada penelitian ini menunjukkan bahwa sebagian besar responden berumur 20-30 tahun, yaitu sebanyak 24orang $(60,0 \%)$. Kenyataan ini sangatlah sesuai dengan teori yang ada, yang mana kenyataan dilapangan menunjukkan semakin dewasa umur responden semakin penuh pertimbangan.

Dan dari hasil survey di lapangan banyak ibu yang tingkat pendidikannya rendah,Dalam hal ini terdapat kesenjangan antara teori dan keadaan di lapangan, yang 
menunjukkan bahwa tingkat pendidikan sangat berpengaruh bagi seseorang dalam bersikap, membuat suatu keputusan, memahami, serta mengambil tindakan terhadap suatu hal. Hal tersebut menandakan semakin rendah tingkat pendidikan,maka ibu akan semakin bersikap negatif dalam menerima informasi tentang alat kontrasepsi.

Hasil temuan dilapangan di dapatkan dari 40 ibu yang menjadi responden kemungkinan penyebab rendahnya pemilihan alat kontrasepsi implant adalah pendidikan ibu yang masih rendah tentang alat kontrasepsi. Makin tinggi tingkat pendidikan seseorang, maka makin mudah dalam memperoleh dan menerima informasi. Pada penelitian ini menunjukkan bahwa sebagian besar yaitu $(60,0 \%)$ responden berstatus sebagai lulusan Sekolah Dasar (SD) Dalam hal ini spesifik antara teori dan kenyataan yang ada di lapangan, di mana kenyataan yang ada di lapangan untuk responden yang berpendidikan rendah sangat sulit untuk menerima informasi dan tidak tahu atau sangat bingung alat kontrasepsi apa yang mau di gunakan nantinya.

Seseorang yang bekerja pengetahuannya akan lebih daripada seseorang yang tidak bekerja, karena dengan bekerja seseorang akan punya banyak informasi sehingga menambah pengetahuannya. Seseorang yang be-kerja di sektor formal memiliki akses yang lebih baik terhadap berbagai informasi termasuk kesehatan (Depkes RI, 1998) pada penelitian ini sebagian be-sar responden bekerja ibu sebagai petani yaitu sebanyak 24 responden $(60,0 \%)$

Sehingga ibu dalam berpikir lebih rasional serta dalam memilih alat kontrasepsi. Hal ini di karenakan juga kurangnya informasi tentang alat kontrasepsi, sehingga para ibu pun cendrung datang apabila ada informasi tentang kesehatan, jadi semakin banyak informasi yang di dapat, akan semakin tahu ibu dalam memilih alat kontrasepsi yang menurut ibu itu lebih baik.

Dari uraian diatas dapat disimpulkan bahwa informasi dan motivasi seseorang dapat dipengaruhi oleh faktor informasidan motivasi ibu. Hal ini, sesuai dengan hasil dari analisis data yang menggunakan SPSS 20.0 yang menunjukkan adanya hubungan informasi alat kontrasepsi dengan motivasi pemilihan alat kontrasepsi implant di Desa Poreh Kecamatan Lenteng Kabupaten Sumenep Tahun 2018.

\section{KESIMPULAN}

1. Sebagian besar responden di desa poreh mempunyai informasi tentang alat kontrasepsi yang kurang di Desa Poreh Kecamatan Lenteng Kabupaten Sumenep Tahun 2018.

2. Sebagian besar responden di desa poreh mempunyai motivasi dalam pemilihan alat kontrasepsi implant negatif di Desa Poreh Kecamatan Lenteng Kabupaten Sumenep Tahun 2018.

3. Ada hubungan informasi tentang alat kontrasepsi dengan motivasi pemilihan alat kontrasepsi implant di Desa Poreh Kecamatan Lenteng Kabupaten Sumenep Tahun 2018.

\section{SARAN}

1. Teorit is

Dari hasil penelitian ini, diharapkan agar seluruh masyarakat agar lebih menambah pengetahuan tentang pentingnya alat kontrasepsi implant. Salah satu keuntungan dari alat kontrasepsi implant yaitu perlindungan jangka panjang sampai 3-5 tahun.

2. Praktis

a. Bagi Peneliti

Diharapkan peneliti lebih mempelajari lagi tentang penyebab ibu tidak menggunakan alat kontrasepsi implant.

b. Pelayanan kesehatan

Hendaknya selalu meningkatkan konseling dan penyuluhan tentang pentingnya pengetahuan tentang alat kontrasepsi ke tenaga kesehatan.

c. Bagi Institusi Pendidikan

Diharapkan bisa sebagai masukan untuk meningkatkan mutu pendidikan kesehatan terhadap alat konrasepsi khususnya kontrasepsi implant. Dan Hendaknya penelitian ini dapat dijadikan sebagai salah satu sumber pengetahuan dalam pendidikan tentang masalah hubungan informasi tentang alat kontrasepsi dengan motivasi pemilihan alat kontrasepsi implant. 
d. Bagi Masyarakat

Masyarakat dapat rnencari informasi tentang alat kontrasepsi sehingga masyarakat mau menggunakan alat kontrasepsi implant, tanpa adanya paksaan dari orang lain.

e. Bagi Peneliti Berikutnya

Perlu dilakukan penelitian lebih lanjut tentang hubungan alat kontrasepsi dengan pemilihan alat kontrasepsi implant dengan variabel yang belum diteliti dalam penelitian ini. Diharapkan bisa meningkatkan pengetahuan dan kemampuan peneliti dalam melaksanakan penelitian.

\section{DAFTAR PUSTAKA}

Arikunto (2006). Prosedur Penelitian. Jakarta : Rineka Cipta

Aziz A (2007). Metode Penelitian Penulisan Ilmiah. Jakarta : Salemba Medika.

A. Azis A. Hidayat (2007). Pendidikan dan Perilaku Kesehatan. Jakarta : PT Rineka Cipta.

Alimul H, A Aziz. (2002). Metode Penelitian Keperawatan Dan Teknik Analisis Data. Jakarta: Salemba Medika.

Arikunto ,Suharsimi. (2010). Prosedur Penelitian Suatu Pendekatan Praktek.Yogyakarta: Rineka Cipta.

Arikunto, Suharsimi. (2002). Prosedur Penelitian Suatu Pendekatan Praktek.Yogyakarta: Rineka Cipta Hartanto.2003. Buku Acuan Pelayanan Kontrasepsi. Jakarta : ISBN
Hidayat, A.A.A. 2007. Metode Penelitian Keperawatan dan Teknik Analisis Data. Jakarta : Salemba Medika

Hurlock, Elizabeth. 1998. Perkembangan Anak. Jakarta : Erlangga Http://id.wikipedia.org/wiki/motivasi. Diakses tanggal 17-04-2017

Musdalifah, Mukhsen Sarake, Rahma (2013) Faktor Yang Berhubungan Dengan Pemilihan Alat Kontrasepsi Hormonal Pasutri . Makassar : UNHAS

Notoatmodjo, S. 2003. Pengantar Perilaku dan Pendidikan Kesehatan. Jakarta : Rineka Cipta.

Notoatmodjo (2005). Metodologi Penelitian Kesehatan. Jakarta : PT. Rineka Cipta

Notoatmdjo , Soekidjo. (2012). Pendidikan dan perilaku Kesehatan. Jakarta : Rineka Cipta, EGC.

Nursalam (2003). Konsep dan Penerapan Metodologi Penelitian Keperawatan. Jakarta : Salemba Medika

Nursalam (2011). Konsep dan Penerapan Metodologi Peneitian Keperawatan. Jakarta : Salemba Medika.

Nursalam \& Pariani, S. 2001. Pendekatan Praktis Metodologi Riset Keperawatan. Jakarta : Sagung Seto.

Rakhmad , Jalaluddin (2005). Psikologi Komunikasi. Bandung: PT. Remaja Rosdakarya

Sardiman, A.M. 2003. Interaksi dan Motivasi Belajar Mengajar. Jakarta 